\title{
A GESTÃO ESTRATÉGICA DO CONHECIMENTO COMO INSTRUMENTO DE GERAÇÃO DE VALOR: UM ESTUDO DE CASO EM INSTITUIÇÃO PRIVADA DE ENSINO BÁSICO
}

http://dx.doi.org/10.5902/2318133835465

\author{
Chateaubriand Pinto Bandeira Júnior ${ }^{1}$ \\ Alejandro Martins Rodriguez ${ }^{2}$ \\ Catarina Medeiros Bandeira ${ }^{3}$ \\ Lucas Borchartt Bandeira ${ }^{4}$ \\ Lucinaldo dos Santos Rodrigues ${ }^{5}$
}

\begin{abstract}
Resumo
As instituições de ensino básico no Brasil têm enfrentado constantes desafios provocados por mudanças no ambiente organizacional. Desse modo, o objetivo deste trabalho foi estudar a gestão estratégica do conhecimento como instrumento de valor em uma instituição privada de ensino. $O$ universo do estudo foi constituído por uma escola de ensino básico da cidade de Campina Grande no Estado da Paraíba. A abordagem desenvolvida foi quanti-qualitativa e o enfoque utilizado foi exploratório-descritivo. Para a coleta de dados foi realizada uma entrevista semi-estruturada com os colaboradores e feitas observações de campo. Os resultados encontrados na pesquisa destacaram a necessidade de valorização da subjetividade dos colaboradores no contexto organizacional, cujas atitudes é resultado dos seus processos cognitivos, tais como: inteligência, competência, experiência, capacidade, motivação, socialização e liderança, que vão emergindo no seu cotidiano e são disponibilizados à organização. Pelas nossas observações e conclusões, o comportamento do colaborador, enquanto agente ativo da organização, faz com que ambos colaborador e organização - tenham benefícios intrínsecos.

Palavras-chave: capital intelectual, organização, educação.

\section{STRATEGIC MANAGEMENT OF KNOWLEDGE AS AN INSTRUMENT FOR VALUE GENERATION IN PRIVATE BASIC EDUCATION INSTITUTIONS: A CASE STUDY}

\begin{abstract}
Notably, primary education institutions in Brazil have faced constant challenges brought about by changes in the organizational environment. Thus, the objective of this work was to study the Strategic Management of Knowledge as an instrument of value in a private educational institution. The universe of the study was constituted by a basic school of the city of Campina Grande in the State of Paraíba. The approach developed in this work was quanti-qualitative and the approach used was exploratory-descriptive. For the data collection a semi-structured interview with the collaborators was made and field observations were made. The results found in the research emphasized the need to value the subjectivity of employees in the organizational context, whose
\end{abstract}

\footnotetext{
${ }^{1}$ Universidade Federal da Paraíba, Brasil. E-mail: medeirosbandeira@uol.com.br.

2 Universidade Federal de Pelotas, Brasil. E-mail: alimartins@gmail.com.

3 Universidade Federal da Paraíba, Brasil. E-mail: catmbio@hotmail.com.

4 Universidade Federal da Paraíba, Brasil. E-mail: lucasborchartt@yahoo.com.br.

5 Universidade Federal da Paraíba, Brasil. E-mail: lucinaldo.s.r@gmail.com.

Regae: Rev. Gest. Aval. Educ.

Santa Maria

v. 8

n. 17

Pub. contínua 2019

p. $1-15$
} 
attitudes are the result of their cognitive processes, such as: intelligence, competence, experience, capacity, motivation, socialization and leadership that emerge in their and are made available to the organization. From our observations and conclusions, the behavior of the employee as an active agent of the organization causes both (employee and organization) to gain in terms of intrinsic benefits.

Key-words: intellectual capital, organization, education. 


\section{Introdução}

ercebe-se, no âmbito organizacional, uma maior atenção para os indivíduos que fazem parte do seu quadro de colaboradores, principalmente entre os indivíduos que exercem cargos de confiança na escala hierárquica das organizações. Observa-se o indivíduo já não como um elemento operacional, mas como um elemento ativo que, por meio da sua inteligência busca ideias, empenha sua criatividade na busca de soluções para os diversos problemas que surgem no seu cotidiano organizacional, sejam eles emergentes do ambiente interno ou externo, tendo em vista o aumento da competição entre as organizações de ensino.

Desse modo, as instituições privadas de educação básica no Brasil, assim como outras organizações, tem se deparado com constantes desafios provocados por mudanças no ambiente organizacional. É neste ambiente propriamente dito, as escolas de ensino privado, onde se observa uma grande competição, criando-se a necessidade da busca por melhorias da qualidade e aumento na produtividade do ensino, sem que se possa negligenciar o foco na eficiência organizacional (Sampaio, 2011).

No contexto do funcionamento das organizações das instituições privadas de ensino acompanhar as determinações políticas e legais para um melhor entendimento e compreensão de ameaças e oportunidades do mercado (Batista, 2009). Entende-se, desse modo, na visão do autor, que a sobrevivência no ambiente competitivo da educação privada brasileira depende de saber viver em um espaço aberto para a concorrência.

Acredita-se que as instituições privadas de ensino básico lidam com o conhecimento no seu cotidiano organizacional, entretanto, pode-se ir mais além, ou seja, elas podem gerar conhecimento e centrarem sua razão de poder existir, em função de serem as responsáveis por vender conhecimento através dos seus serviços. Desse modo, Ferasso e Saldanha (2011), enfatizam que o conhecimento é um dos atributos mais importantes de uma organização, principalmente em instituições de ensino, e o gerenciamento desse conhecimento tem despertado interesse quanto à obtenção de vantagens competitivas ocasionadas pelo processo de mudanças em um determinado mercado.

Por outro lado, as organizações estão se tornando mais exigentes em relação à contratação de seus novos colaboradores, optando por contratar o profissional já qualificado, tentando reduzir custos e aumentar suas receitas, para tornarem-se competitivas sem elevar significativamente as despesas com a capacitação dos seus colaboradores (Rodrigues, 2003). Para Edvinsson e Malone (1998), uma organização sem a dimensão de um fator humano bem sucedido fará com que todas as demais atividades de criação de um valor não dêem certo, independentemente do nível de sofisticação tecnológica e do saber que ela tenha. Desse modo, percebe-se o acontecimento gradativo de uma grande mudança do modo de gerir as diferentes instituições, e com ela, a necessidade urgente por parte das organizações contemporâneas para descobrirem onde se encontra esse novo profissional e qual o seu papel dentro dessa nova era do conhecimento.

Por outro lado, é importante ressaltar que de nada vale uma avançada estratégica baseada no conhecimento que priorize, dentre outros aspectos, o fortalecimento das equipes de trabalho, a políticas de incentivos, aquisição de equipamentos de alta 
tecnologia e detenção de um excelente quadro de colaboradores - criativos, autônomos e experientes -, se não houver, por parte da organização, certo equilíbrio entre as suas estratégias organizacionais e as expectativas individuais.

Acredita-se que é a gestão do conhecimento, hoje caracterizada pelo capital intelectual das empresas, esse novo elemento que pode trazer mudanças dentro das instituições, principalmente nas áreas de tecnologia da informação, de telecomunicações, e de ensino, ao envolver uma combinação de ativos intangíveis - competências, informações, estratégias, relacionamentos, patentes, propriedade intelectual e experiências -, que se transformam em benefícios quantitativos e qualitativos no contexto do funcionamento das organizações.

Conforme Nonaka e Takeuchi (2008), o enfoque no papel profissional das pessoas e no valor de seu saber mudou e requer novas estratégias de gestão dentro das organizações; desse modo, as empresas passam a se preocupar não só com o que sabem, mas precisam saber o que os outros sabem mediante a análise das empresas concorrentes. Com base nesse pensamento percebe-se a importância de transformar 0 conhecimento tácito em explícito, a serviço da organização, saindo da perspectiva do individual para uma perspectiva muito mais abrangente, do coletivo, se apropriando e institucionalizando o conhecimento.

Em se tratando de gestão do conhecimento deve-se ter em mente o caráter contínuo e dinâmico das ações ao longo do tempo. Para Nonaka e Takeuchi (2008), o conhecimento não pode ser considerado uma verdade absoluta, porque o mesmo é dinâmico; diz respeito às crenças e compromissos que ocorrem em função de uma atitude, perspectiva ou intenção específica e, portanto, está relacionado à ação em determinado contexto. Assim, a gestão do conhecimento nas organizações deve considerar esta dinamicidade do recurso conhecimento, visualizando a sustentabilidade da vantagem competitiva (Nadai; Calado, 2015). Dentro desta compreensão, observa-se a importância de gerar crenças, compromissos, situações e interações apropriadas para que as informações possam ser convertidas em conhecimentos adquiridos que transitem pelas organizações e assim possam contribuir e influenciar futuros julgamentos, comportamentos, atitudes e tomadas de cisão, melhorando o aspecto gerencial da instituição, o que em termos gerais pode ser definido como capital intelectual de uma empresa.

Edvinsson e Malone (1998) acreditam que o capital intelectual é capaz de manter uma empresa atrativa e sustentável em sua criação. Compõem o capital intelectual: o capital humano, representado pelo conhecimento, experiência, poder de inovação e habilidades dos indivíduos, e o capital estrutural, que compreende os equipamentos, softwares, bancos de dados, entre outros fatores físicos. Stewart (1998) enfatiza que além desses - capital humano e estrutural -, o capital de clientes - relacionamento com aqueles que, de algum modo, contribuem para o aporte financeiro da instituição, principalmente pela compra de bens ou serviços - deve ser considerado como um fator-chave na composição do capital intelectual. 
Segundo Colenci Jr et al. (2008), o crescimento acelerado de instituições privadas de ensino nas últimas décadas tem motivado diversos estudos, pesquisas e reflexões sobre a dinâmica de como ocorre essa evolução e qual a sua influência no desenvolvimento da educação do país. Assim, esse crescimento tem levantado uma série de propostas sobre qual modelo de gestão é o mais adequado à demanda apresentada.

Desse modo, conforme os tópicos acima descritos sobre o crescimento acelerado das instituições privadas de ensino no Brasil e da concorrência gerada por causa desse crescimento, que partimos na busca de uma reflexão acerca do papel da gestão do conhecimento na perspectiva de funcionamento de uma instituição particular de ensino, levando-se em consideração a importância de se ampliar as discussões acerca da gestão do conhecimento e da sua relação com a administração estratégica, na busca por uma melhor compreensão de como esse processo acontece no ambiente das escolas particulares de ensino, foco desse estudo, onde há uma exigência constante na busca de renovação do seu modo de gestão e de busca constante por modos e metodologias mais eficientes e eficazes de atuação. Desse modo, o objetivo do presente trabalho foi analisar se a gestão estratégica do conhecimento pode ser, de fato, um instrumento de geração de valor estratégico e competitivo em uma instituição privada de ensino básico, no município de Campina Grande/PB.

\section{Metodologia}

A presente pesquisa se caracteriza como de natureza qualitativa e buscou levantar dados sobre a gestão do conhecimento, tendo com foco a administração estratégica dos ambientes externo e internos de competição em uma organização de ensino privada. Quanto aos procedimentos utilizados na coleta de dados, esta pesquisa se classifica como sendo um estudo de caso.

O universo da pesquisa selecionada foi o Colégio Aplicação, nome fantasia usado para designar a instituição particular de ensino, enquanto organização social que fundamenta a sua razão de existência pautada no conhecimento. A instituição em questão encontra-se a dezessete anos no mercado, possui duas unidades nas cidades de Campina Grande/PB três unidades em João Pessoa-PB. O objeto de estudo foi delimitada a unidade destinada a Educação Infantil e Fundamentais I e II, localizada na cidade de Campina Grande/PB. Ao todo, a referida unidade atende a um público de 1.834 alunos.

O referido Colégio possui, ao todo, um efetivo de 264 funcionários, dos quais 133 são professores e os demais ocupam as mais distintas funções. Apesar de compreendermos que uma instituição se faz pelo conjunto de ações de todos os seus agentes, optou-se por restringir o universo a ser investigado às pessoas que, de algum modo, estavam ligados à gestão da instituição, tendo em vista que o objetivo geral da pesquisa se refere aos aspectos da gestão institucional.

Nos diferentes modelos de capital intelectual que geram a gestão de conhecimento dentro das empresas, as variáveis que têm sido mais citadas são: capital estrutural estrutura interna -, capital humano - pessoas - e capital de relacionamentos - estrutura externa. Para a construção do modelo conceitual de referência foram observados os seguintes passos: 1) leitura das principais obras sobre o capital intelectual e de gestão do conhecimento, propostos pelos modelos de Nonaka e Takeuchi (1997), Davenport e Prusak (1998), Probst, Raub e Romhardt (2002), Rossato (2002), Choo (2003), Terra 
(2005) e Angeloni (2008), por considerarmos que esses autores melhor sintetizam e agregam as principais categorias teóricas a cerca da gestão do conhecimento; 2) seleção dos elementos mais significativos para investigação da gestão do conhecimento dentro da proposta por cada um dos modelos estudados; 3) busca da fusão dos conceitos em comum, referenciados nas obras analisadas.

No que se refere à elaboração do questionário o mesmo foi organizado tentando aglutinar as questões de acordo com as especificações das dimensões e categorias formadoras da gestão do conhecimento e do capital intelectual. Entretanto, por ser um tema muito abrangente, no presente trabalho foi avaliado apenas o capital humano, restringindo-se aos aspectos relacionados à inovação, e o capital estrutural, referindo-se a aspectos relacionados à infraestrutura.

Para validação do instrumento de coleta de dados elaborado, foi feita a análise do roteiro da pesquisa por dois pesquisadores da área de gestão de conhecimento, a fim de ser averiguada a clareza e pertinência do conteúdo, evitando dessa forma possíveis ambiguidades na compreensão do texto, por parte dos entrevistados. Outro instrumento para validação dos resultados foi o uso de técnica da triangulação, que tem por objetivo básico abranger de forma exaustiva e ampla o uso da descrição, explicação e compreensão do objeto em estudo (Triviños, 1987), o que resultou na combinação de diferentes recursos metodológicos - entrevistas, observação subjetiva análise de documentos - para a investigação do fenômeno.

Antes da realização das entrevistas foi realizado um pré-teste, aplicando-se o roteiro de entrevista aleatoriamente a dois funcionários da unidade de ensino, tendo como finalidade verificar aspectos como o grau de clareza e de compreensão do mesmo.

O trabalho de coleta de dados em campo teve início com o encaminhamento ao setor de gestão de pessoas da instituição, onde foram obtidas algumas informações básicas sobre a instituição, principalmente no que se refere à estrutura, funcionamento $\mathrm{e}$ quadro funcional. Mediante as informações prestadas foi feita a seleção dos colaboradores que seriam entrevistadas, de acordo com o organograma de funções e competências apresentado pela empresa.

Objetivando uma maior imersão e consequente compreensão das particularidades do universo pesquisado, foram feitas várias incursões ao estabelecimento de ensino ao longo de cinco meses. Tais visitações nos possibilitaram a observação informal do modo como os sujeitos se portavam e relacionavam-se entre si, relacionamento interpessoal, condições ambientais, bem como aspectos da infraestrutura organizacional. Tais observações contribuíram para a construção da análise e diminuíram o distanciamento que podia existir entre a pura e simples realização das entrevistas sem essa vivência parcial do modos operandi da instituição objeto de estudo. Nessas oportunidades também tivemos acesso a material impresso institucional - folderes, encartes, cartazes, banners, etc. - que subsidiaram a análise documental, além das conversas informais com funcionários.

Desde o primeiro contato com o entrevistado tentou-se pautar a condução do trabalho considerando alguns dos procedimentos sugeridos por Paiva (2005), a exemplo das orientações a cerca da postura e conduta do entrevistador a fim de estabelecer uma relação de respeito e confiabilidade com 0 entrevistado, o que pôde resultar em depoimentos mais ricos e reveladores. No primeiro contato com o funcionário a ser 
entrevistado era realizada a apresentação do pesquisador e dos objetivos do trabalho. Posteriormente, era entregue uma folha com as instruções gerais para a realização da entrevista, sendo solicitada a autorização para gravá-la. Pretendia-se com isso favorecer um primeiro contato e criar uma atmosfera mais confortável e menos resistente para iniciar a entrevista.

Foi elaborado um termo de consentimento livre e esclarecido para explicar aos entrevistados o objetivo da pesquisa e assim obter o máximo de fidedignidade nos dados coletados. Manteve-se o total sigilo quanto à identificação dos mesmos, resguardando dessa forma o seu anonimato. Quanto à condução das entrevistas buscou-se flexibilizar a sequência dos questionamentos, bem como complementar as indagações à medida que iam surgindo novos questionamentos que pudessem enriquecer a posterior análise dos dados, o que classifica a presente pesquisa como semi-estruturada (Manzini, 1990).

Nesse estudo foi disponibilizado um conjunto de questionamentos com o objetivo de descrever a gestão do conhecimento tendo como foco a administração estratégica dos ambientes externo e interno de competição da organização. Portanto, esta tendência caracteriza a natureza do enfoque utilizado na investigação como um estudo exploratóriodescritivo. Sob essa ótica, o presente trabalho fundamentando-se na pesquisa qualitativa, buscando investigar uma temática ainda não explorada.

A metodologia que norteia o presente estudo tem na abordagem qualitativa a base da proposta de investigação, por se tratar de uma abordagem metodológica voltada para a ação direta entre pesquisador e sujeito de pesquisa. A ênfase que foi dada no método qualitativo para este trabalho tem a ver com o nível de profundidade do tema, bem como com as técnicas de entrevista e a observação participante que ocorreu no período de condução das conversas.

Para as entrevistas, utilizou-se a técnica de análise de conteúdo, visando a identificar os elementos mais significativos do discurso e compreender os sentidos transmitidos que tivessem elementos abordados na gestão do conhecimento. Nesse tipo de análise duas vertentes são imprescindíveis: a definição de categorias de análise e a unidade de registro (Paiva, 2005). As principais categorias elencadas foram capital humano e capital estrutural. Essas categorias foram agrupadas por serem munidas de significados que se destacam naturalmente tendo uma mesma base de questionamento.

A técnica de analise de conteúdo realizada em três etapas cronológicas: a préanálise: organização e seleção do material, exploração do material: estudo aprofundado do material, levantando-se hipóteses e a teoria estudada, e o tratamento dos resultados. Nessa última etapa, partindo da inferência e da interpretação utilizou-se reflexões, intuição e ponderações buscando compreender as relações nos dados e nas informações levantadas, tendo como base o referencial teórico ou apontando novos caminhos teóricos (Paiva, 2005). As entrevistas foram gravadas e posteriormente transcritas, a fim de facilitar a posterior análise dos discursos.

Durante a fase de transcrição houve a exaustiva audição, repetidas vezes, na busca de uma tradução fiel dos depoimentos. Por se tratar de um roteiro de entrevista semiestruturada, com relativa variedade de questões abordadas em cada uma das entrevistas, foi feita a análise e categorização das respostas, de acordo com o tema abordado, a fim de facilitar a posterior análise dos conteúdos. Uma vez finalizada a etapa de categorização das respostas, teve início a análise dos discursos propriamente dita, na 
tentativa de capturar o sentido mais significativo embutido nas falas dos entrevistados. Durante essa fase ocorreram consultas e retomada do estudo de textos que embasaram o nosso referencial teórico.

Durante a discussão e apresentação dos resultados, foi feito o uso eventual de citações e trechos significativos de alguns dos depoimentos a fim de melhor respaldar as conclusões elencadas, conforme recomenda Aires (1973). Tal encaminhamento permite ao pesquisador uma maior proximidade com o significado do conteúdo, uma vez que a formação das categorias de análise se fazem a partir da compreensão do conteúdo (Laville; Dionne, 1999).

\section{O capital humano}

Segundo Mayo (2003), sem as pessoas todos os elementos estruturais de uma empresa, tanto os relativos aos clientes como da própria organização, poderiam se desintegrar e deixariam de crescer. Quando realizada da forma correta, a gestão de pessoas torna-se uma excelente vantagem competitiva, pois a empresa que tem funcionários satisfeitos funciona inteiramente melhor.

Define-se o capital humano como o conjunto de recursos incorporado nas pessoas cujos talentos, competências, atitudes, habilidades e capacidade de inovar são direcionados para a criação de produtos e serviços de qualidade, com o intuito de atrair novos clientes e fidelizar os mais antigos, procurando satisfazê-los da maneira possível (Marques; Palmeira, 2011).

Para o presente trabalho foi avaliado o capital humano sob a ótica da capacidade de inovar. Para a condução de nossas observações, partimos do pressuposto de que a inovação não é gerada apenas por avanços e resultados em pesquisa e desenvolvimento que geram novas tecnologias, maquinários e ferramentas. As práticas gerenciais antecedem e, em princípio, podem contribuir para a capacidade de inovação da empresa, de forma que a inovação pode ser de natureza empresarial e não simplesmente de natureza tecnológica (Cunha, 2005).

$\mathrm{Na}$ instituição objeto de estudo verificamos que uma das formas de inovar, na visão dos seus colaboradores, se refere à elaboração de projetos pedagógicos que criam maneiras alternativas de ensino, sendo estas consideradas mais dinâmicas. Esse aspecto foi enaltecido pela grande maioria dos entrevistados como sendo uma forma de inovação, sobretudo quanto à forma e metodologias de ensino. Nesse aspecto, a escola em questão possui uma grande variedade de projetos pedagógicos o que, de certa forma, termina sendo um diferencial e permite, na maioria das vezes, uma maior integração com a família do aluno. Segundo a maioria dos entrevistados, sobretudo entre aqueles que também trabalham ou já trabalharam em outras empresas do mesmo segmento, esse é um dos fatores que diferem a instituição de seus concorrentes mais voltados para uma proposta de ensino essencialmente tradicional. Ao todo conseguimos identificar ao menos vinte projetos apenas no site institucional, abrangendo as mais diferentes áreas: cultura, esportes, lazer, social, etc.

Outro fator relevante referente à execução desses projetos e de uma política pedagógica diferenciada na cidade, e talvez no Estado, é que eles promovem uma maior interação da escola com a família dos alunos e com a comunidade de uma forma geral, 
gerando reflexos para a imagem da empresa perante a sociedade. Nesse aspecto, a escola pesquisada passa a ser tida como referência em termos de inovação na maneira de ensinar.

Como nos foi revelado por alguns colaboradores, alguns desses projetos têm sido, inclusive copiados por outras instituições concorrentes, a exemplo do projeto que conscientiza os alunos para a importância da adoção de uma dieta saudável. Em tempos em que se discute os riscos de uma dieta desequilibrada para a saúde as pessoas, em especial das crianças, a escola ganha destaque por trazer à tona o debate e o combate ao problema.

A escola pesquisada também tem procurado inovar se preparando para a oferta de um ensino inclusiva e de qualidade voltado para as crianças com necessidades especiais. Não são todas as escolas da cidade que são referência no atendimento especializado desse público. Segundo uma das coordenadoras entrevistadas, nos últimos dois anos houve um aumento considerável de cinco para sessenta e cinco alunos portadores de alguma necessidade especial, o que demonstra que os esforços realizados em termos de capacitação dos colaboradores e do uso de metodologias para atender alunos com necessidades especiais tem trazido retorno para a escola.

Muito embora a inclusão de alunos com necessidades especiais esteja prevista na lei n. 13.146, de 6 de julho de 2015, poucas escolas têm se preparado para atender essa nova demanda. Entretanto, consideramos que o aumento considerável da procura pela instituição pesquisada é sinônimo de que a mesma vem se estabelecendo como uma referência. Esse seria outro aspecto a ser explorado nas campanhas publicitárias da instituição: o de ofertar um ensino includente, especializado e de qualidade, algo que não conseguimos identificar de maneira tão explícita no material de divulgação a que tivemos acesso.

Uma forma de inovar apontada pelos entrevistados e que conseguimos identificar na nossa incursão em campo é que a empresa vem buscando sempre fazer uso de novas tecnologias, sobretudo pelo uso de redes sociais para uma melhor comunicação e interatividade com seus clientes. Além do uso da já tradicional Agenda, também utilizada como principal canal de comunicação entre a família, a escola tem buscado inovar ao fazer uso de novas ferramentas de e-mail e de aplicativos de mensagem para comunicação direta com os pais, disponibilizando um espaço virtual de registro de atividades, onde, em caso de falta do aluno, o mesmo pode consultar o que foi ministrado em sala de aula e quais foram as atividades realizadas naquele dia. No nosso ponto de vista, tudo isso é inovação e um diferencial da forma tradicional pela qual a maioria das escolas mantém seu relacionamento com a família.

Durante as entrevistas foram comuns menções de que a escola sempre tenta focar no futuro, antevendo mudanças antes mesmo de se criarem as necessidades. Como alguns definiram: buscar sempre antever o que vai acontecer daqui a cinco anos. Para isso a escola tem procurado participar de feiras de tecnologia a nível nacional, tentando sempre trazer softwares voltados tanto para a área administrativa, quanto para a de serviços, além de manter-se antenada com o que têm sido desenvolvido por outras escolas de referência das regiões Sul e Sudeste do Brasil, especialmente em escolas situadas no Estado de Minas Gerais, Estado em que se encontra a maior parte das instituições com as quais a escola promove esse tipo de parceria. Pelo que averiguamos 
junto à administração, sobretudo a direção geral, a escola está sempre buscando, em outros centros, novas ferramentas e recursos em inovação, o que a coloca sempre a um passo a frente da concorrência. Isso ficou demonstrado pela análise do discurso de alguns entrevistados ao serem perguntados sobre de que forma, na opinião deles, a instituição se diferenciava da concorrência:

"Eu acho assim, com inovação, sabe? Até, usa-se um termo, a escola tenta ser protagonista, eu lembro bem que quando começaram com a história do ENEM, quando começou mesmo, nenhuma escola acreditava que isso fosse acontecer, e isso, aqui a gente já começou a trabalhar nessa visão, mesmo ainda não estando fundamentada, sendo uma situação que vai acontecer, então a gente já tem que tá pensando se isso acontecer." (Entrevistado 1).

"Olha... já estou aqui a quase seis anos, e o que eu tenho visto sempre aqui na escola é essa busca por novidades, por fazer diferente do que estão fazendo por aí; essa é sempre uma preocupação nossa. Procuramos ver o que tem de novidade nas feiras, nos encontros aí fora... em outras escolas do Sul e Sudeste e tentamos adaptar pra nossa realidade. Nenhuma outra escola da região consegue fazer isso: está sempre trazendo novidades. Terminamos sendo referência na região." (Entrevistado 2)

Outro ponto relevante quanto à busca pela inovação na prestação dos seus serviços se refere à contratação de empresas de consultoria especializadas em diferentes segmentos que orientam e ajudam a traçar novas diretrizes para o funcionamento da escola, sobretudo quando se refere às novidades tecnológicas e metodológicas, ajudando a trazer o que de mais novo está sendo trabalhado ou usado em instituições de ensino no país. Foi por meio de estudos de demanda perante os clientes que foram implantados 0 ensino em tempo integral e o ensino de Inglês.

No caso do ensino de inglês, ministrado de forma extracurricular, em horário de aula adicional pelo qual os pais de alunos pagam uma mensalidade extra adicionada ao pagamento mensal habitual da mensalidade regular do aluno, a escola ofereceu inicialmente o serviço de forma terceirizada, havendo a participação de outra empresa que era responsável por essa área de atuação. Posteriormente, a própria escola passou a oferecer esse serviço, tendo inclusive absorvido alguns colaboradores da outra empresa com a qual firmava parceria como parte integrante do seu capital humano. Oferecer um curso de Inglês ou mesmo o ensino em tempo integral, são inovações que não estão presentes, ao menos até 0 presente momento, nos principais estabelecimentos concorrentes da referida escola. Ela consegue, portanto, oferecer um ensino diferenciado nesse aspecto, e atender a uma nova demanda do mercado:

"Em educação não podemos ser estáticos, porque a educação é algo que se renova em todos os sentidos, se renova no sistema de ensino, no seu fazer. O aluno de hoje é totalmente diferente do aluno de cinco anos atrás. Precisamos sempre pensar em estratégias pra melhorar nossa prestação de serviço. Buscar trazer inovações que nos diferenciem das outras empresas" (Entrevistado 3). 


\section{O capital estrutural}

O capital estrutural inclui toda a estrutura organizacional que apoia a produtividade do capital humano, incluindo-se aí os equipamentos de informática, os softwares, os bancos de dados, as patentes e as marcas registradas. Portanto, é tudo que pertence à empresa, constituindo-se o ambiente instalado pela organização, sendo composto pelos procedimentos internos e externos que existem dentro da instituição (Francini, 2002). No presente trabalho, no que se refere ao capital estrutural da empresa estudada, visou-se à avaliar como a infraestrutura é, na perspectiva dos entrevistados e das nossas observações, um instrumento de geração de valor.

Segundo Oliveira e Beuren (2003), a infraestrutura compreende as tecnologias, as metodologias e os processos empregados, tais como cultura organizacional, sistema de informação, métodos gerenciais, aceitação de risco, banco de dados dos clientes, etc. No presente trabalho solicitou-se aos entrevistados para comentar sobre a infraestrutura encontrada na organização para realização de seus trabalhos.

Segundo os entrevistados, e conforme também foi possível averiguar in loco, a escola apresenta uma estrutura física bem ampla. Percebe-se ao centro o espaço administrativo e em outro ponto uma pequena igreja faz parte do espaço. Nesse último aspecto vale salientar que no próprio material de divulgação da escola, folders e revistas institucionais, a escola se auto intitula como promotora de valores cristãos. Esse aspecto mostra-se relevante, considerando que duas das maiores concorrentes da instituição na cidade pesquisada são escolas confessionais tradicionalmente cristãs.

Por definição, segundo Camargo (2007, p. 7), instituições tradicionalmente cristãs são instituições de cunho religioso que também se dedicam a educação formal. Ao promover valores cristãos a instituição pesquisada consegue atender essa demanda específica de mercado na cidade pesquisada e vemos, nesse aspecto, outro diferencial da referida instituição, pois diferente de suas principais concorrentes do segmento, ela promove valores cristãos, uma tendência em crescimento nas escolas, conforme Schunemann (2009), sem se deter especificamente a determinada corrente religiosa, estritamente católica ou protestante, por exemplo, conseguindo atrair um público mais amplo de clientes.

Como infraestrutura a escola ainda oferece laboratórios, biblioteca, teatro, arena de esportes, piscina coberta aquecida, horta orgânica - onde os alunos eventualmente tem aulas sobre cultivo de alimentos saudáveis -, campo de futebol e mini-fazenda - com animais a exemplo de pôneis, coelhos, galinhas, cabras, vaca -, nesse último aspecto, eventualmente, as crianças realizam passeios de montaria e de charrete. Essa infraestrutura é um dos argumentos do que seria um fator diferencial que contribui para a aprendizagem dos alunos:

"O nosso colégio prima por um espaço agradável e ambientes de convivência interessantes....quem conhece essa escola sabe que o espaço de convivência e o espaço pedagógico são espetaculares, então isso ajuda na convivência e ajuda na aprendizagem das crianças e dos adolescentes." (Entrevistado 4) 
A infraestrutura, além de auxiliar no aspecto da aprendizagem, também contribui para a retenção dos alunos. Em se tratando de instituição particular de ensino, isso pode implicar na fidelização dos clientes. Segundo Dias, Theóphilo e Lopes (2010), em estudos realizados em instituições públicas de ensino superior, estrutura deficiente é um dos aspectos que elevam os índices da evasão de alunos.

Durante a entrevista também se questionou se a instituição realiza investimentos em equipamentos ou tecnologias para auxiliar nos trabalhos realizados. Segundo os entrevistados isso se faz de forma frequente pelos rotineiros investimentos em novas tecnologias e equipamentos, tais como quadro interativo, projetores de multimídia e sistemas de áudio e vídeo. Segundo um dos colaboradores, quando se tem estrutura adequada e recursos disponíveis, é possível apresentar um bom desempenho e uma melhor produtividade, alcançando mais facilmente os resultados objetivados pelos funcionários e pela organização.

As inovações tecnológicas acontecem tanto no setor de administração, quanto na comunicação com os pais por meio do armazenamento de dados dos alunos que frequentemente é atualizado, como também na área de ensino. Os gestores participam regularmente de feiras tecnológicas nacionais e tem procurado acatar as sugestões do setor de $\mathrm{Tl}$ e da equipe pedagógica que mantém intercâmbios frequente com outras instituições de ensino a exemplo de universidades e institutos especializados em tecnologias.

Em relação ao ensino, além das aulas estruturadas com equipamentos e tecnologias que possam auxiliar na melhor forma de passar o conteúdo, os docentes também utilizam os laboratórios para ministrar aulas práticas e a estrutura física como um meio lúdico no sentido de promover uma melhor fixação do conhecimento pelos alunos. Para Beltrame e Moura (2009), a harmonia entre os usuários e o ambiente é um aspecto que deve ser bem relacionado, sendo necessário que haja uma interação entre o espaço físico, atividades pedagógicas e comportamento humano.

\section{Considerações finais}

Pelo que foi averiguado nas nossas incursões e pela análise dos discursos de seus colaboradores, acreditamos que a referida instituição de ensino tem desenvolvido ações sistemáticas de inovação pelos colaboradores, o que tem contribuído para que ela permaneça sendo uma das principais instituições desse segmento na cidade e mesmo no Estado.

Os colaboradores configuram-se, de fato, como um passível intangível, de relevante impacto. Na perspectiva dos mesmos a infraestrutura é um dos pontos fortes da instituição, não sendo necessário realizar adequações, uma vez que são realizados investimentos periódicos em equipamentos, tecnologia, softwares e em equipamentos visando ao melhor desempenho dos alunos e a maior satisfação de seus usuários.

No contexto analisado, a gestão estratégica do conhecimento tem contribuído para que a referida instituição de ensino básico se mantenha em posição de destaque no mercado. 


\section{Referências}

ANGELONI, Maria Terezinha. Organizações do conhecimento: infra-estrutura, pessoas e tecnologia. São Paulo: Saraiva, 2008.

BATISTA, Fábio Ferreira. Modelo de gestão do conhecimento para a administração pública brasileira: como implementar a gestão do conhecimento para produzir resultados em benefício do cidadão. Brasília: Ipea, 2009.

BELTRAME, Mauria Bontorin; MOURA, Graziella Ribeiro Soares. Edificações escolares: infra-estrutura necessária ao processo de ensino e aprendizagem escolar. Travessias, Cascavel: Unioeste, v. 3, n. 2, 2009, p. 1-15.

CAMARGO, Eduardo Vieira. A influência da capelania no crescimento espiritual da escola. Del Plata, Espanha: Universidades Adventista Del Plata, 2007, 95f. Tese (doutorado em Educação). Facultad de Humanidades, Educación y Ciencias Sociales Extensión del Seminario Adventista de España.

CHOO, Chun Wei. A organização do conhecimento: como as organizações usam a informação para criar significado, construir conhecimento e tomar decisões. São Paulo: Senac, 2003.

COLENCI JUNIOR, Afredo; SPIGOLON, Ana Lúcia; PREZOTO, Marco Anselmo de Godoi; SÁES, Maria Elizete Luz. Gestão estratégica das instituições de ensino superior: uma contribuição ao melhor desempenho no caso brasileiro, São Paulo, 2008. Disponível em https://www.researchgate.net/publication/238779034_A_Gestao_Estrategica_das_Instituic oes_de_Ensino_Superior_uma_contribuicao_ao_melhor_desempenho_no_caso_brasileir o. Acesso em 14 jul. 2018.

CUNHA, Neila Conceição Viana da. As práticas gerenciais e suas contribuições para a capacidade de inovação em empresas inovadoras. São Paulo: USP, 2005, 157f. Tese (doutorado em Administração). Faculdade de Economia, Administração e Contabilidade, Universidade de São Paulo.

DAVENPORT, Thomas Hayes; PRUSAK, Lawrence. Conhecimento empresarial: como as organizações gerenciam seu capital intelectual. Rio de Janeiro: Campus, 1998.

DIAS, Ellen; MORAES, Christine; THEÓPHILO, Carlos Renato; LOPES, Maria Aparecida Soares. Evasão no ensino superior: estudo dos fatores causadores da evasão no curso de Ciências Contábeis da Universidade Estadual de Montes Claros - Unimontes - MG. CONGRESSO USP DE INICIAÇÃO CIENTÍFICA EM CONTABILIDADE, 7, 2010, São Paulo. Anais... São Paulo: Êxito, 2010, p. 1-16.

JULIA, Dominique. A cultura escolar como objeto histórico. Revista Brasileira de História da Educação, Campinas, n. 1, 2001, p. 9-43.

EDVINSSON, Leif; MALONE, Michael Shawn. Capital intelectual: descobrindo o valor real de sua empresa pela identificação de seus valores internos. São Paulo: Makron Books, 1998.

FERASSO, Marcos; SALDANHA, Jorge Alberto Velloso. A gestão do conhecimento aplicada em instituições de ensino superior: o caso da associação catarinense de fundações educacionais. Revista Gestão Universitária na América Latina - GUAL, Florianópolis, 2011, p. 51-69.

FRANCINI, William Sampaio. A gestão do conhecimento: conectando estratégia e valor para a empresa. Revista de Administração de Empresas - RAE (eletrônica), São Paulo: FGV, v. 1, n. 2, 2002, p. 1-16. 
LAVILLE, Christian; DIONNE, Jean. Construção do saber: manual de metodologia da pesquisa em ciências humanas. Belo Horizonte: UFMG, 1999.

Lima, Renata Fernandes de Oliveira. Gestão estratégica de pessoas: uma ferramenta poderosa. SIMPÓSIO DE EXCELÊNCIA EM GESTÃO E TECNOLOGIA, 8, 2011. Anais... Resende: AEDB, 2011.

LIMA, Renata Fernandes de Oliveira. Gestão estratégica de pessoas: uma ferramenta poderosa. SIMPÓSIO DE EXCELÊNCIA EM GESTÃO E TECNOLOGIA, 8, 2011, Resende. Anais... Resende: AEDB, 2011, p 1-13.

MARQUES, Joaquina. Helena. Vaz Langort; PALMEIRA, Eduardo. Mauch. Capital intelectual como diferencial competitivo nas organizações. Contribuciones a la Economia. Disponível em http://www.eumed.net/ce/2011b. Acesso em 10 ago. 2018.

NADAI, Fernanda Castro; CALADO, Luiz. O conhecimento como recurso estratégico: caracterizando uma organização intensiva em conhecimento (OIC). SEMINÁRIOS EM ADMINISTRAÇÃO, 8, 2005, São Paulo. Anais... São Paulo: FEA-USP, 2005.

NONAKA, Ikujiro; TAKEUCHI, Hirotaka. Criação de conhecimento na empresa: como as empresas japonesas geram a dinâmica da inovação. Rio de Janeiro: Campus, 1997.

NONAKA, Ikujiro; TAKEUCHI, Hirotaka. Gestão do conhecimento. Porto alegre: Bookman, 2008.

OLIVEIRA, Joel Marques; BEUREN, Ilse Maria. O tratamento contábil do capital intelectual em empresas com valor de mercado superior ao valor contábil. Revista Contabilidade \& Finanças - USP, São Paulo, n. 32, 2003, p. 81-98.

PAIVA, Simone Bastos. Abordagem gerencial do capital intelectual em uma organização baseada em conhecimento: o caso Sebrae/PB. João Pessoa: UFPB, 2005. 406f. Tese (doutorado em Adminstração). Programa de Pós-Graduação em Administração, Universidade Federal da Paraíba.

PROBST, Gilbert; RAUB, Steffen; ROMDHARDT, Kai. Gestão do conhecimento: os elementos construtivos do sucesso. Porto Alegre: Bookman, 2002.

RODRIGUES, Lucinaldo dos Santos. Os indicadores engajamento organizacional dos indivíduos na perspectiva da gestão do conhecimento. Florianópolis: UFSC, 2003. $275 f$. Tese (doutorado em Engenharia da Produção). Programa de Pós-Graduação em Engenharia da Produção, Universidade Federal de Santa Catarina.

ROSSATO, Maria Antonieta. Gestão do conhecimento: a busca da humanização, transparência, socialização e valorização do intangível. Rio de Janeiro: Interciência, 2002.

SAMPAIO, Helena. O setor privado de ensino superior no Brasil: continuidades e transformações. Revista Ensino Superior Unicamp, Campinas: Unicamp, v. 2, n. 4. 2011, p. 28-43.

SCHUNEMANN, Haller Elinar Stach. A educação confessional fundamentalista no Brasil atual: uma análise do sistema escolar da IASD. Revista de Estudos da Religião, 2009, p. 71-97.

STEWART, Thomas. Capital intelectual: a nova vantagem competitiva das empresas. Rio de Janeiro: Campus, 1998.

TERRA, José Cláudio Cyrineu. Gestão do conhecimento: o grande desafio empresarial. Rio de Janeiro: Elsevier, 2005.

TRIVIÑOS, Augusto Nibaldo Silva. Introdução à pesquisa em ciências sociais: a pesquisa qualitativa em educação. São Paulo: Atlas, 1987. 
Chateaubriand Pinto Bandeira Júnior é professor no Centro de Ciência Humanas, Sociais e Agrárias da Universidade Federal da Paraíba.

Orcid: https://orcid.org/0000-0003-4392-541X.

Endereço: Rua Frei Damião de Bozzano, 508 - 58402-595 - Campina Grande - PB Brasil.

E-mail: medeirosbandeira@uol.com.br.

Alejandro Martins Rodriguez é professor na Universidade Federal de Pelotas.

Orcid: https://orcid.org/0000-0002-3283-8807.

Endereço: Rua Gomes Carneiro, 1 - 96.010-610 - Pelotas - RS - Brasil.

E-mail: aljmartins@gmail.com.

Catarina Medeiros Bandeira é professora no Centro de Ciência Humanas, Sociais e Agrárias da Universidade Federal da Paraíba.

Orcid: https://orcid.org/0000-0003-3909-3403.

Endereço: Rua Antônio Bezerra Paz, 43 - 58401-654 - Campina Grande - PB - Brasil.

E-mail: catmbio@hotmail.com.

Lucas Borchartt Bandeira é professor no Centro de Ciência Humanas, Sociais e Agrárias da Universidade Federal da Paraíba.

Orcid: https://orcid.org/0000-0002-9098-9160.

Endereço: Rua Antônio Bezerra Paz, 43 - 58401-654 - Campina Grande - PB - Brasil.

E-mail: lucasborchartt@yahoo.com.br.

Lucinaldo dos Santos Rodrigues é professor no Centro de Ciências da saúde da Universidade Federal da Paraíba.

Orcid: https://orcid.org/0000-0002-9662-4349.

Endereço: Avenida Espírito Santo, 585/1103 - 58030-110 - João Pessoa - PB - Brasil.

E-mail: lucinaldo.s.r@gmail.com.

Recebido em 11 de dezembro de 2018.

Aceito em 6 de janeiro de 2019.

(c) (i) 